\title{
Formação do psicólogo: uma breve análise dos modelos de intervenção
}

Este artigo aborda a trajetória histórica das Faculdades de Psicologia do Rio de Janeiro, buscando configurar o campo ao qual vem sendo submetido o futuro especialista "psi" no interior das instituiçōes de ensino superior. Outra questão presente é se a cultura psicológica constitui-se num referencial comum de análise e se a natureza das instituições formadoras interfere no sentido dado à formação profissional.

\section{Deise Mancebo \\ Professora Adjunta do Instituto de Psicologia da Universidade do Estado do Rio de Janeiro. Trabalharam no levanta- mento e análise dos dados, nesta etapa da pesquisa: Adriana Miranda de Castro e Leandro Vieira Osuna, bolsistas de iniciação científica da UERJ e do CNPq, respectivamente, e Alexandre Teixeira dos Santos, mestrando do Instituto de Psicologia da UERJ.}

\section{INTRODUÇĀO}

Este trabalho reporta-se a parte dos resultados de uma pesquisa intitulada "História dos Cursos de Psicologia no Rio de Janeiro (1956/1978): a Cultura Psicológica nas Instituiçōes de Ensino Superior" 2 .O tema da investigação é a análise da trajetória histórica das Faculdades de Psicología no Rio de Janeiro, desde a criação do curso da Pontifícia Universidade Católica do Rio de Janeiro, em 1953, o primeiro a ser idealizado no Brasil, chegando à década de 70, ao final da qual identificamos mudanças profundas na sociedade brasileira e nas instituiçōes de ensino superior, a partir da reorganização da sociedade civil e redemocratização das instituiçōes, inclusive das escolas de educação superior do país.

A intenção mais geral da pesquisa é configurar o campo ao qual vem sendo submetido o futuro especialista "psi" no interior das instituiçōes de ensino superior, no período histórico selecionado. Para o alcance deste objetivo temos mapeado a filiação teórica e concepções dos formadores (professores, supervisores), identificado e analisado os principais dispositivos, concepçōes hegemônicas e ferramentas recomendadas aos futuros psicólogos. Enfim, tem-se procurado definir os "modelos" profissionais apresentados aos perscrutadores das intimidades, neste período histórico.

Parto da hipótese de que este campo de formação universitária do psicólogo, enquanto porta-de-entrada para a construção do profissional, constitui-se num território que compartilha da "cultura psicológica". Esta última temática tem sido amplamente discutida, por cientistas sociais (Castel, 1978; Duarte, 1986; Foucault, 1979; Machado, 1978 e Velho, 1986) e psicanalistas (Costa, 1979; Figueira, 1985; Figueiredo, 1992; Russo, 1993). Seus estudos destacam a intensa difusão das práticas "psi" nas camadas médias urbanas de nossa sociedade, após os anos 60, a partir da consolidação de um "ethos" individualista e "intimista", no qual os especialistas "psi" são um efeito e mais um dispositivo difusor, com um grande potencial de intervenção no espaço social.

O outro parâmetro analítico da pesquisa baseia-se no seguinte pressuposto: se a "cultura psicológica", em expansão, por ocasião do surgimento das primeiras escolas superiores de Psicologia, constituí-se num referencial comum de análise, por outro lado, o fato de os cursos estarem inseridos em instituiçōes com características diversas - universidades, faculdades isoladas, instituições públicas, privadas, religiosas, comunitárias - deve ter-Ihes marcado o desenvolvimento, as formas institucionalizadas construídas e o sentido dado à formação dos profissionais.

Neste trabalho, com resultados ainda parciais da pesquisa mais geral, discutirei as características mais marcantes dos cursos de Psicologia e das críticas a eles apresentadas, apontadas pelos próprios psicólogos.

\section{METODOLOGIA E FONTES}

Para a discussão da temática escolhida, os cursos de Psicologia e suas características principais, recorremos a fontes diversas. Primeiramente, foi localizada, organizada e analisada toda a legislação referente à profissão e aos cursos de Psicologia.

Os periódicos do Conselho Federal de Psico- 
logia (CFP) constituíram um segundo grupo de fontes primárias analisadas. Refiro-me às 26 revistas editadas pelo Conselho Federal de Psicologia, sob o título Psicologia: ciência $e$ profissão, desde o início de sua publicação, em 1979, à data atual. Nestes exemplares, foram selecionados, para leitura e análise, os artigos que se referissem, mesmo que indiretamente, à formaçāo dos psicólogos em nível de graduação e pós-graduação e à criação da profissāo.

Com o objetivo de fazer um mapeamento inicial dos formandos de Psicologia nas instituiçōes de ensino superior do Rio de Janeiro, foi feito o levantamento, leitura e análise estatística dos processos de inscrição dos psicólogos no CRP-05. Foram analisados 4148 processos existentes, entre o ano de 1974, data em que o Conselho começou efetivamente a funcionar, e o ano de 1980, limite temporal da pesquisa.

Por fim, fontes secundárias - livros, artigos e teses referentes à formação do psicólogo também foram utilizadas. ${ }^{3}$

\section{OS CURSOS DE PSICOLOGIA: CARACTERÍSTICAS E CRÍTICAS}

Desde o início do século passado, as práticas psicológicas já eram exercidas no país, e dentre estas o ensino de "psychologia" (Massimi, 1990; Penna, 1992). Os cursos eram ministrados então, no âmbito de diversas áreas do conhecimento: Teologia, Direito, Medicina, Pedagogia e Filosofia e era com este perfil fragmentado e "adaptado" a outros saberes, que ocorria o repasse e construção do pensamento psicológico entre nós.

No entanto, o marco assinalado pela maior parte do material trabalhado foi a promulgação da Lei 4119, de 27 de agosto de 1962. Constituiu-se no primeiro diploma legal específico sobre cursos de formação de psicólogos, seguido por ato do Conselho Federal de Educação que, através do Parecer no 403 de 1962, fixou o currículo mínimo e a duração do curso de Psicologia, com vigência a partir do ano seguinte. Deste modo, a regulamentaçāo da profissão, conforme tradição em nosso país, ocorre através do mesmo ato legal que normatiza os cursos de Psicologia. Nos primeiros anos de existência enquanto profissão, a Psicologia viveu uma fase de consolidação dos seus limites em relação ao campo médico e aos "saberes leigos" sobre as "faculdades mentais". Nossa análise deste período da história da Psicologia apontou, contudo, para a seguinte consideração: a delimitaçāo legal deste novo campo do saber foi marcada por lutas corporativas quanto à ocupação de espaços institucionais e no mercado de trabalho, não tendo propriamente operado cortes no sentido da construçāo de um novo saber. Sem maiores problematizaçōes ou conflitos, os conhecimentos psicológicos acumulados por profissionais médicos, educadores, engenheiros, filósofos, desenvolvidos dentro ou fora do espaço acadêmico, foram assimilados acriticamente.

Do mesmo modo, naturalmente que sem o aval explícito da corporação, muitas práticas consideradas misticas, logicamente infundadas, também foram trazidas para a nova profissão. Esta "matriz" não-científica era (ou é) especialmente detectada quando se tratava "do-que-fazer" da prática psicológica em sentido estrito. Nestas, a sobreposição de técnicas dissociadas de um corpo teórico, que não têm a possibilidade de se submeter a uma problematização e confronto com outras argumentaçōes teóricas, transformaram-se, com muita facilidade, num pensamento obscurantista e mistificador, cujo único critério avaliativo era o senso-comum. Outro aspecto que deixou marcas na profissão foi o fato de seus cursos de formação e sua clientela crescerem desmesurada e desordenadamente, logo nos primeiros anos. Esta situação tornou-se mais complexa quando se sabe que os necessários embates no campo epistemológico não foram tratados com a devida atenção, na medida em que a corporação, em seus momentos definitórios, optou pela busca de soluçōes acomodatícias, à justificação de projetos de grupos, que visavam muito mais à manutenção do status já atingido, por alguns de seus membros, do que propriamente pelo enfrentamento teórico.

No entanto, $a$ análise das fontes surpreendeu-me, desde o início, pelo fato de as referências à formação do psicólogo, em seus aspectos histórico, legal, características, críticas e análises aparecerem com uma freqüência bastante elevada.

Dai a idéia de, neste trabalho, realizar uma análise desta produção: uma reflexão sobre os modelos de intervenção psicológica, a partir das críticas dos próprios psicólogos 
sobre os cursos de formaçāo.

\section{1 - DA FORMACÃO TEÓRICO-PRÁTICA}

Na maioria dos trabalhos analisados, os conhecimentos teóricos ministrados nos cursos de Psicologia são apontados como tendo um tratamento fragmentado $e$ desvinculado da prática e da realidade de nosso país.

Na pesquisa, por exemplo, realizada por Bastos e Gomide (1989), onde foram entrevistados 2448 psicólogos, muitos dos quais formados nos anos 70 , os resultados foram contundentes:

"...ao analisarmos as respostas dos nossos entrevistados verificamos que, no que se refere à fundamentação filosófica, metodológica e científica, mais de 50\% deles estão insatisfeitos com os conhecimentos adquiridos na graduação e este índice aumenta para $64,4 \%$ quando se refere à experiência cientifica". (Bastos \& Gomide, 1989: 12)

O caráter fragmentado dos conhecimentos teóricos oferecidos nos cursos, na realidade, refletem a própria situação da Psicologia na qualidade de disciplina autônoma. Seria difícil uma certa organicidade nos cursos, já que a própria disciplina psicológica não se constitui num corpo estruturado de conhecimentos, como freqüentemente pode ser identificado nas ciências naturais. É reconhecida a diversidade, e mesmo antagonismo, entre as diferentes abordagens psicológicas, bem como o caráter particular com que esta disciplina tenta se constituir como ciência. Figueiredo (1995) assinala, inclusive, "que nem temos uma delimitacào unívoca do campo, uma compreensão partilhada do que é fundamentalmente nosso objeto". (Figueiredo, 1995: 96-97)

Este problema é agravado pela falta de prioridade com que a pesquisa é tratada nos cursos de graduação, caracterizando um quadro de formação passiva, onde o aluno transforma-se em ouvinte e repetidor dos conhecimentos "prontos" que lhe são repassados.

Este aspecto traduz outra questāo básica da formação acadêmica brasileira. Conforme Francisco e Bastos (1992):

"...somos apenas consumidores - no máximo adaptadores - de conhecimentos gerados pela ciência do primeiro mundo. A pro- dução é reduzida e está muito aquém das demandas postas por um contexto cultural especifico. $A$ atividade de pesquisa, ainda incipiente e mal distribuída geograficamente carece do fortalecimento de grupos, da consolidação de tradiçōes, do estabelecimento de linhas consistentes de investigação que dêem a cumulatividade necessária a qualquer empreendimento científico. Especialmentelo calizada nos programas de pós-graduacão, a atividade de pesquisa tem o seu impacto reduzido, inclusive nos cursos de graduação, da maioria dos quais se encontra ausente." (Francisco \& Bastos, 1992: 216)

Mesmo os atuais cursos de pós-graduação, que por excelência deveriam valorizar o desenvolvimento de novos conhecimentos, estão, em muitos aspectos, contaminados pelo afã da técnica, tomando o formato, em muitos casos, de verdadeiros cursos de especialização, complementos naturais da graduação defeituosa. Com poucas exceçōes, não vêm se constituindo num espaço para a formaçāo do magistério superior e o desenvolvimento de pesquisas. (Botomé, Della Coleta \& Matos , 1988)

No entanto, as maiores críticas detectadas nos trabalhos percorridos, têm as práticas (ou estágios) como foco central de análise. Uma das restriçōes aponta para a pequena quantidade (em termos de carga horária de estágio), a pouca diversidade (somente Clínica, Trabalho e Escolar) e o franco predomínio da área Clínica .

No levantamento dos registros de psicólogos no CRP-05, expostos na Tabela 1 e Gráfico 1, os dados não confirmam estatisticamente esta hegemonia do modelo clínico ra realização de estágios pelos estudantes de Psicologia. Apesar da Clínica ser a área predominante nas respostas dadas $(39,20 \%)$ vem seguida de perto pela áreas da Psicologia do Trabalho (31,40\%) e Escolar (21,05\%). No entanto, isto não invalida os resultados encontrados nas outras pesquisas publicadas pelo Conselho Federal de Psicologia, segundo as quais o modelo clínico individual penetra e impregna outros campos de estágio/trabalho existentes.

Esta realidade torna-se mais intranqüila quando se considera que - com a proliferação dos cursos de graduação em instituiçōes de ensino superior privadas, à época do regime militar - os arranjos organizacionais montados não propiciavam o oferecimento de estági- 
Tabela 01

os. Não era raro que o aluno simplesmente informasse a realização de um estágio através de uma declaração emitida por algum outro estabelecimento e a prática, a princípio tão valorizada num curso profissionalizante, transforma-se num mero procedimento burocrático. Neste sentido, é importante registrar o grande número de profissionais inscritos no CRP-05, que não se pronunciaram sobre a realização de estágios $(79,09 \%) .{ }^{4}$

As instituições formadoras, portanto, têm atuado como reprodutoras de um modelo básico de atuação - as atividades clínicas desenvolvidas em consultórios particulares, na perspectiva de formação de profissionais liberais. Ratificando esta afirmativa, a profunda dicotomia entre os aspectos teóricos e práticos apresentada nos cursos, não admira que prolifere entre os alunos (e futuros profissionais) a busca de suporte "teórico" alhures nos misticismos, nas iniciativas individuais/ isoladas ou na busca de soluçōes técnicas imediatistas, em especial quando atuando em ambientes não afeitos ao modelo dominante que thes é ensinado, e mal.

Carvalho (1984), em pesquisa realizada no Estado de São Paulo, encontrou nas 367 entrevistas realizadas, queixas permanentes $(86 \%)$ quanto à desarticulação entre teoria e prática, nos cursos de Psicologia. Na análise deste material conclui que esta ênfase na oposiçāo teoria e prática, sugere uma concepçāo de formaçāo profissional que prevalece na população estudada:

" a da formação especializada, ou da compartimentalização das áreas de atuação, como se, para atuar em diferentes situacōes de trabalho, o psicólogo devesse conhecer diferentes referenciais de análise e diferentes técnicas... Esse modo de pensar a formacão profissional se aproxima perigosamente, de acordo com nosso (seu) ponto de vista, de um modelo de formacão técnica, entendida como o treinamento do profissional no uso de instrumentos prontos, designados para cada situaçāo específica de trabalho." (Carvalho, 1984: 8-9)

Deve-se ainda salientar que esta suposta oposição ou dicotomização entre formação teórica e prática não aparece gratuitamente na cabeça do aluno e pelo menos, em alguma medida, deve refletir as próprias características dos cursos de Psicologia, sua estrutura curricular, seu caráter fragmentado, e, talvez,

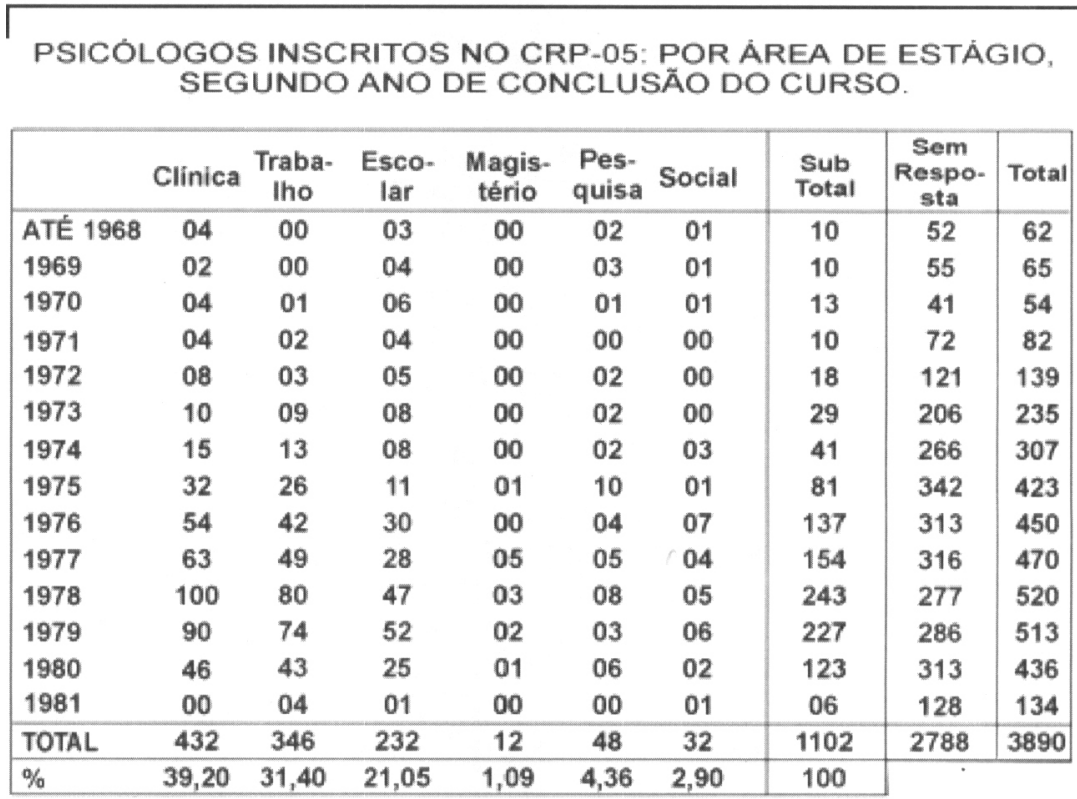

FONTE: CRP-05, Processos de inscrição de psicólogos de 1974 a 1980

principalmente, sua desvinculação da nossa realidade.

Gráfico 01

\section{2 - DA RELAC̣ĀO COM A SOCIEDADE}

Muitos artigos, senão a maioria, apontam o fato de os cursos serem alheios à realida-

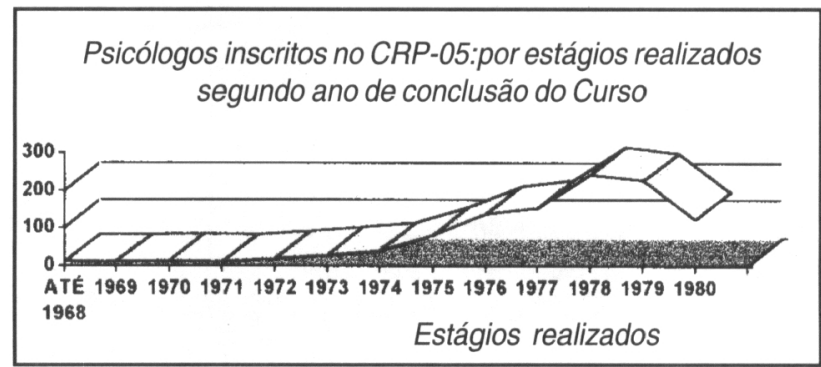

de brasileira. Na sua relação com os saberes já constituídos no campo "psi", não efetuaram um corte, ao contrário, mantiveram as tradicões anteriores, não havendo empenho no desenvolvimento de pesquisas que pudessem instrumentalizar criticamente o "novo" profissional para o enfrentamento das nossas especificidades. Desse modo, a formação "psi" nos cursos de Psicologia tem modelado um tipo de exercício profissional cujo alcance social é pequeno, pelo fato de recaírem no modelo hegemônico (clínico-individual), dificultando a possibilidade de diversificação do exercício da Psicologia. (Francisco \& Bastos, 1992: 213)

Cabe registrar que a ênfase na formação clínico-individual, tem um paralelo nas práticas dos profissionais. Na Tabela 2 e no Gráfico 2 pode-se observar que a área de atuação predominante em todo o período
Fonte: CRP-05, Processos de inscrição de psicólogos de 1974 a 1980

${ }^{3}$ No trato das fontes escritas, foram ut/lizadas as formulaçōes teórico-metodológicas da "Análise de DisCuISO" IORLANDI, E. P. $A$ linguagem $e$ seu funclonamento: as formas do discurso. 2.ed. Campinas: Pontes, 1987; ORLANDI, E. P. (org). Gestos de leitura: da História no discurso. Campinas: Editora da UNICAMP, 1994.), principalmente, pelo relevo que dispensa ao processo $e$ às condiçōes da produção discursiva.

${ }^{4}$ Este percentual é bastante elevado, mesmo considerandose que esta resposta era espontânea na ficha de inscrição que os psicólogos preenchiam para requerer o seu registro. 
Tabela 02

PSICOLOGOS INSCRITOS NO CRP-05: POR ÁREA DE ATUAÇÃO SEGUNDO ANO DE CONCLUSÃO DO CURSO DE PSICOLOGIA.

\begin{tabular}{|l|c|c|c|c|c|c|c|c|c|c|}
\hline & Clínica & $\begin{array}{c}\text { Traba- } \\
\text { lho }\end{array}$ & $\begin{array}{c}\text { Esco- } \\
\text { lar }\end{array}$ & $\begin{array}{c}\text { Magis- } \\
\text { tério }\end{array}$ & $\begin{array}{c}\text { Pes- } \\
\text { quisa }\end{array}$ & $\begin{array}{c}\text { Social } \\
\text { ATE 1968 }\end{array}$ & $\begin{array}{c}\text { Atuaçäo } \\
\text { fora da } \\
\text { psicologia }\end{array}$ & $\begin{array}{c}\text { Sub } \\
\text { Total }\end{array}$ & $\begin{array}{c}\text { Sem } \\
\text { Respo- } \\
\text { sta }\end{array}$ & Total \\
\hline 1969 & 25 & 03 & 07 & 06 & 01 & 01 & 01 & 41 & 29 & 70 \\
1970 & 20 & 03 & 08 & 08 & 01 & 00 & 00 & 49 & 25 & 74 \\
1971 & 23 & 16 & 10 & 10 & 03 & 01 & 00 & 63 & 37 & 100 \\
1972 & 46 & 21 & 25 & 19 & 03 & 03 & 02 & 119 & 55 & 174 \\
1973 & 79 & 44 & 42 & 17 & 02 & 04 & 01 & 189 & 82 & 271 \\
1974 & 74 & 62 & 53 & 12 & 09 & 03 & 06 & 219 & 119 & 338 \\
1975 & 115 & 90 & 69 & 18 & 14 & 05 & 08 & 319 & 156 & 475 \\
1976 & 196 & 105 & 71 & 14 & 05 & 09 & 06 & 406 & 88 & 494 \\
1977 & 208 & 159 & 69 & 14 & 08 & 05 & 08 & 471 & 51 & 522 \\
1978 & 204 & 124 & 66 & 12 & 06 & 09 & 07 & 428 & 101 & 529 \\
1979 & 194 & 99 & 47 & 05 & 00 & 04 & 10 & 359 & 125 & 484 \\
1980 & 151 & 75 & 40 & 05 & 02 & 04 & 03 & 280 & 272 & 552 \\
SEM DPLOMA & 07 & 04 & 04 & 03 & 00 & 01 & 05 & 24 & 43 & 67 \\
SEM DATA & 85 & 42 & 35 & 12 & 01 & 02 & 10 & 187 & 379 & 566 \\
\hline TOTAL & 1449 & 854 & 554 & 157 & 56 & 51 & 67 & 3188 & 1585 & 4773 \\
\hline$\%$ & 45,45 & 26,79 & 17,38 & 4,92 & 1,76 & 1,60 & 2,10 & 100 & & \\
\hline
\end{tabular}

FONTE: CRP-05, Processos de inscrição de psicólogos de 1975 a 1980

\section{Gráfico 02}

pesquisado (até 1980 ) foi a Clínica (45,45\%), seguida pela do Trabalho $(26,79 \%)$ e a área Escolar (17,38\%).

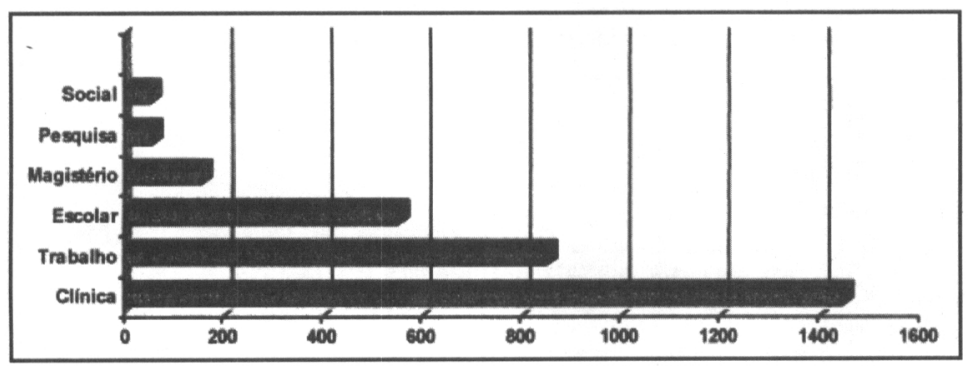

O psicólogo, diante da formação que rece beu, aspira ao ideal liberal de

Fonte: CRP-05, Processos de inscrição de psicólogos de 1975 a 1980. atuar com os seus "iguais", os estratos médios urbanos. No entanto, em função das dificuldades cada vez maiores do mercado. termina prestando seus serviços também junto às camadas mais desfa-vorecidas da população, sem qualquer problematização prévia sobre esta aproximação. Uma situação que poderia significar uma positiva expansão da atuação psicológica para as camadas populares transforma-se em martírio para o profissional, que, ao se refugiar na "técnica aprendida", pode, com relativa facilidade, transmutar a sua nova realidade de trabalho em patologias e desvios.

Nas pesquisas patrocinadas pelo Conselho Federal de Psicologia (1994), as estatísticas apontaram para uma insignificante presença de trabalhos do tipo inovador. Deste modo, concluem que as instituiçōes formadoras têm reproduzido, com raras exceçōes, um modelo básico de atuação profissional, apresentando aos futuros profissionais as tarefas tradicionalmente confiadas aos psicólogos, nos seus diversos ambientes de trabaIho.

No entanto, em pequena escala, nos últimos quinze anos, têm sido desenvolvidos modos alternativos de atuaçāo. Conforme Basto e Achcar (1994), o sentido destas mudanças, ainda pontuais, seriam os citados a seguir: (1) os esquemas conceituais, tradicionalmente centrados no plano individual (indivíduo a-histórico, isolado do seu contexto social) estariam se ampliando para uma concepção de sujeito visto na sua interdependência com o contexto sócio-cultural; (2) as fontes de conhecimento, norteadoras das práticas, estariam caminhando da perspectiva unidisciplinar para a multidisciplinaridade, abarcando, em especial, os conhecimentos produzidos no campo da Sociologia e da Antropologia; (3) a intervenção psicológica centrada na ação do psicólogo isolado sobre um indivíduo, dentro de uma perspectiva curativa (ou de remediação), estaria evoluindo para uma atuação em equipes multiprofissionais, centrada em contextos, em grupos, com características preventiva e de prospeccão; (4) os recursos técnicos adotados, restritos e originários basicamente no âmbito da própria Psicologia, estariam se diversificando com a absorção de técnicas que extrapolam o campo propriamente "psi"; (5) a clientela atingida pelo campo "psi", predominantemente de classe média e com algum poder aquisitivo estaria mais diversificada, atingindo classes mais populares; (6) a postura "consumista" diante dos conhecimentos, técnicas e práticas, já que gerados em outros contextos e aqui aplicados de forma acrítica, estaria sendo substituída por uma posição mais "crítica", diante da preocupação em gerar conhecimentos e tecnologia apropriados à realidade em que atuam e, por fim, (7) as "práticas alternativas" vêm ampliando o compromisso ético do profissional, originalmente voltado para o atendimento de necessidades individuais ("preocupaçāo humanista") e agora mais preocupado com o engajamento pela transformação social.

Esses novos delineamentos, trazidos ao campo "psi", provocam consequiências diretas para a formação acadêmica, no sentido da superação das formas extremamente limitadas com que tem se desenvolvido o ensino da Psicologia. As fontes analisadas apontam 
para a necessidade de integrar, dentro dos próprios cursos, o vasto conjunto de enfoques e abordagens, sem reduzitos a um único enfoque e sem fragmentar mais ainda a fundamentação ora apresentada.

Um outro caminho apresentado é o da ampliação da concepção de ciência que embasa grande parte da produçāo científica na Psicologia. Este seria um requisito importante para permitir a contemplação destas novas práticas psicológicas e para o estabelecimento de um diálogo mais profundo entre a pesquisa em Psicologia, seu ensino e os profissionais.

Na prática, não houve propriamente uma estagnação nos cursos de formação. No entanto, as mudancas ocorridas foram superficiais, desenvolvidas somente nos currículos, abrangendo apenas ampliaçōes de cursos, alterações de carga horária, trocas de disciplinas e modificaçōes do período em que são oferecidas.

Deste modo, fica evidente que as mudanças curriculares realizadas estão aquém dos requisitos apresentados como necessários no parágrafo precedente, distando da possibilidade de atendimento às "queixas" de alunos, professores e profissionais. Parecem ter consistido tão somente num esforço de acomodaçāo ou de busca de um certo equilibrio, no sentido de minimizar a antiga hegemonia da área clínica.

Por fim, cabe destacar alguns dos motivos para o surgimento das chamadas "práticas emergentes", apontadas nas fontes analisadas.

Primeiramente, embora não analisadas com a devida ênfase em vários trabalhos, estão as mudanças sociais, políticas e culturais mais amplas em curso no país. Conforme Bastos e Achcar (1994):

“... consolidam-se neste momento práticas, posturas e concepcóes que foram geradas lentamente ao longo do período autoritário e que encontraram espaço mais propício à sua afirmação a partir do processo de democratizaçāo nos anos 80. Ao se preocupar em olhar a realidade brasileira e em privilegiar os segmentos sociais excluídos ou as camadas populares, alguns psicólogos estariam procurando redimir a profissão pelo modelo, também excludente, que a caracterizou desde os seus primórdios no país." (Bastos \& Achcar, 1994: 266)

O crescente assalariamento do psicólogo, não devidamente ponderado nas fontes consultadas, é outro fator a ser considerado na busca de novas práticas. Resultante de condiçōes econômicas nacionais desfavoráveis, o psicólogo vem-se transformando num trabalhador assalariado, o que "forçou" a uma revisão das práticas anteriormente calcadas no modelo profissional liberal, muitas vezes impregnadas de preconceitos contra 0 trabalho em situação institucional. Nesta busca, alguns psicólogos começaram a se inserir em instituiçōes, o que lhes impôs o relacionamento com outros profissionais, outra clientela, outras práticas e modelos teórico e técnicos. Grande parte dos ainda modestos movimentos de transformação tem sido relacionadas a esta nova inserção dos profissionais.

Por fim, o desenvolvimento das "práticas emergentes" deve ser compreendido a partir da sua dupla motivaçāo: o anselo por atender a uma demanda social mais ampla, mas também uma busca de maior conformidade às características de um mercado de trabalho cada vez mais estreito.

\section{CONSIDERACOŌES FINAIS}

É preciso destacar, primeiramente, o empenho do Conselho Federal de Psicologia, durante várias gestōes, em capitanear a discussāo sobre a formação em Psicologia, transformar as questōes centrais em pesquisas, que reuniram profissionais dos mals sérios de nosso país, e promover a publicação sistemática dos resultados encontrados. Foram destas fontes, reunidas em artigos e livros, que pude desenvolver algumas reflexōes apresentadas no interior deste trabaIho. No sentido de contribuir com a discussão, no entanto, gostaria de finalizar destacando alguns aspectos que considero importantes para futuros aprofundamentos. O primeiro refere-se à constatação presente em praticamente todos os trabalhos, à dicotomia teoria e prática, ou ainda, produção científica versusatuaçāo profissional ou mesmo cursos teóricos versus estágios. Numa análise mais acurada destas facetas da nossa profissão, considero mais indicado referir-se a uma certa complementaridade funcional entre teoria e prática do que afirmar dicotomias ou contradiçōes existentes nos cursos de forma- 
ção. Vejamos: as teorias defasadas de nossa realidade não seriam o grande alimento, na prática, da busca do tecnicismo, do uso de recursos místicos, do ecletismo funcional e mesmo da postura anti-teoricista encontrada em muitos profissionais e alunos estagiários? A ênfase na formação teórica para a clínica dentro do modelo chamado de tradicional, para o atendimento individual e com relações contratuais referentes ao profissional liberal, também não está em contradiçāo com as práticas profissionais. São contundentes as conclusões das pesquisas mais recentes, desta década: ainda há um amplo predomínio das atividades clínicas, marcadas por atuação em consultórios particulares, com dedicação parcial de tempo, onde a psicoterapia é a atividade predominante na sua aplicação em clientela infantil e adulta de classe média. Não é esta também a demanda (espontânea ou não) que os alunos nos trazem para os cursos de Psicologia? Portanto, longe de serem contraditórias, teorias e práticas nos cursos de Psicologia têm-se complementado e retroalimentado.

Esta análise da "dicotomia teoria $X$ prática", parece traduzir, em contrapartida, a insatisfação com este modelo frente a uma demanda potencial e um momento ainda incipiente, mas fértil, de busca de novos paradigmas, com aporte de outros profissionais, de outras práticas e de outras disciplinas.

É preciso, no entanto, estar atento às "práticas alternativas", ou "novos" paradigmas, que se avizinham. Além dos chamamentos já feitos, no interior dos trabalhos que analisamos, com os quais concordo, quanto aos perigos que cercam o pragmatismo técnico, eclético, místico ou anti-teórico, é preciso pensar, em profundidade, algumas das "soluçōes" encontradas e apontadas nos textos. Foram vários os trabalhos que destacaram as mudanças em curso quanto à concepção do fenômeno psicológico: as "novas práticas" estariam caminhando da ênfase no plano individual (indivíduo a-histórico, isolado do seu contexto) para o indivíduo visto na sua interdependência com o contexto sócio-cultural. Quanto à natureza da intervenção, chamou-se atenção para a mudança de foco: do indivíduo "intra-psi" para a intervenção em grupos e em contextos.

Em ambos os casos, no entanto, não perce- bo "cortes" ou "novos" paradigmas. É a mesma concepção naturalizada de indivíduo, dotado de uma intimidade e em choque com o seu meio, anteriormente concebido e tratado isoladamente, que agora reaparece nas "práticas alternativas", dentro de um contexto e tratado em grupo.

As problemáticas mais recentes trazidas principalmente por cientistas sociais (Castel, 1978; Duarte, 1986; Foucault, 1979; Machado, 1978 e Velho, 1986) têm destacado a predominância da configuração de valores individualistas nas modernas sociedades ocidentais. Particularmente, a heterogênea vida metropolitana, com sua variedade de experiências e costumes, contribui para a diferenciação de papéis, para a multiplicação de domínios dando um contorno mais intenso à vida individual. Exposto a experiências diversificadas, visões de mundo contrastantes, o sujeito intensifica sua autopercepção de indivíduo singular. Os discursos e as práticas psicológicas são estimulados, em parte, em conseqüência desse tipo de subjetivação individuada e, por seu turno, estimulam a individualização. Na formaçāo 'psi" tradicional ou "emergente" há uma prevalência do ensino teórico e de técnicas visando à construção de profissionais, cujas subjetividades individuadas estariam aptas à constante observação, avaliação e normatização das intimidades, com o objetivo de reconduzir os futuros clientes ao modelo individualista predominante nas sociedades ocidentais modernas.

Esta supervalorização da categoria individuo, no entanto, é particularmente complexificada em nosso país. São vários os autores que chamam atenção para o caso especial dı Brasil "onde o indivíduo que é a noção nıoderna (encontra-se) superimposta a um poderoso sistema de relações pessoais". (Da Matta, 1983: 180)

Esta discussāo do caso brasileiro assume contornos específicos, nos anos de proliferação das práticas "psi" e dos cursos de formação de psicólogos. Após o golpe militar de 1964, ter-se-ia intensificado o que Jane Russo chama de "individualismo autoritário", resultado de uma negociação entre o modelo hierárquico, que tende a regular as relaçôes sociais no terreno público, e o modelo individualista, que tende a se expandir no espaço do privado, da intimidade. (Russo, 1983)

$\mathrm{O}$ "individualismo autoritário" leva a uma exacerbação do plano psicológico e decorrente 
valorizacão dos fatos da vida pessoal e dos motivos íntimos. Neste substrato cultural, ocorre a intensa expansão social das práticas e teorias psicológicas, dentre as quais o desenvolvimento dos cursos de formação de psicólogos.

Após o golpe militar de 1964 e, particularmente, depois de intensificada a repressão, em 1968, aprofunda-se o processo de individuacão na sociedade brasileira. A familia extensa é decididamente reduzida à família nuclear diante de uma conjuntura que reforcava o projeto individualizante. A interdicão do espaço público aos movimentos reivindicatórios, o medo ao coletivo, diante da ameaca objetiva da repressão, intensificam este processo dos sujeitos procurarem, na família, o território de privacidade, intimidade e felicidade possível e seguro.

Por seu turno, esperava-se da família, com maior freqüência, a contencão dos desvios de seus membros e uma postura mais atenta à relação pais-filhos, à relação entre os cônjuges e aos seus comportamentos.

Estas transformacōes e novas exigências levam a família nuclearizada e seus componentes a perderem parâmetros, as regras que os condur ziam e as práticas anteriormente utilizadas para lidar com situaçōes conflituosas. Cria-se, portanto, uma demanda por intervençōes que possam totalizar e remapear as subjetividades dos seus membros, demanda respondida pelas práticas "psi".

Por seu turno, o saber e a intervençāo psicoló- gica, ao que se pode acrescentar a medicalizaçăo e pedagogização, ajudam na construcão desta familia nuclearizada, com membros individuados, autônomos, ocupados mais intensamente com sua intimidade e privacidade, uma vez que o espaço público lhe está interdito. O psicólogo se autorepresenta e é percebido como agente da "nova felicidade", enquanto um dos artifices de uma subjetividade organizada em torno da liberdade interior, da intimidade. Amplia seu campo de ação às situações de vida ditas normais, valori zando a auto-reflexão e o constante escrutínio do sujeito individuado.

Muito da "produçāo emergente" desenvolvida a partir dos anos 80, cujos eixos inovadores apresentamos sinteticamente, na secão anterior, compartilha deste movimento expansionista da Psicologia, não se constituindo numa construcāo nova, mas na exacerba cão e proliferacão mais minuciosa do velho paradigma individualista.

Por fim, gostaria de destacar que propostas e consideraçōes a serem feitas para mudanças nos cursos de formação não podem se esğotar nos próprios cursos ou profissionais "psi". Nossa formação e os modelos de intervenção que utilizamos são marcas de uma época, a modernidade, e pensá-las criticamente implica, no mínimo, o aporte a outras disciplinas, além do saber "psi", ademais gerado nesta própria matriz.
Castel, R. (1978). O psicanalismo. Rio de Janeiro: Graal.

Duarte, L.F.D. (1986). Da vida nervosa das classes trabalhadoras urbanas. Rio de Janeiro: Zahar. Machado, R. (org) (1978). Danação da norma. Rio de Janeiro: Graal.

Velho, G. (1986). Subjetividade e sociedade. Rio de Janeiro: Zahar.

Costa, J.F. (1979). Ordem médica e norma familiar. Rio de Janeiro: Graal.

Figueira, S. (1985). Cultura da Psicanálise. São Paulo: Brasiliense.

Figueiredo, L.C. (1992). A invenção do psicólogo: quatro séculos de subjetivação. São Paulo: EDUC/ Escuta.

Russo, J. (1993). O corpo contra a palavra: as terapias cosporais no campo psicológico nos anos 80 . Rio de Janeiro: Editora da UFRJ.

Orlandi, E.P. (1987). A linguagem e seu funcionamento: as formas do discurso. $2^{\mathrm{a}}$ ed. Campinas: Pontes

Orlandi, E.P. (org). (1994). Gestos de /eltura: da Histórla no discurso. Campinas: Editora da Unicamp. Massimi, M. (1990). História da Psicologia no Brasil. Sāo Paulo: EPU.

Penna, A.G. (1992). História da Psicologia no Rio de Janeiro. Rio de Janeiro: Imago.
Bastos, A.V.B. (1989). Psicólogo brasileiro: sua atuação e formação profissional. Psicologia Ciência e Profissão, 9, no 1, 12-15.

Figueiredo, L.C. (1995). Revisitando as Psicologias: da epistemiologla à ética das práticas e discursos psicológicos. São Paulo: EDUC.

Francisco, A.L.; Bastos, A.V.B. (1992). Conhecimento, formação e prática, o necessário caminho da integração. Em Conselho Federal de Psicologia. Ps/cólogo brasileiro: construção de novos espaços. (p. 213-216). Campinas: Átomo.

Botomé, S.P.; Della Coleta, J.A.; Matos, M.A. (1988). Contribuições para a definição de uma política científica. Psicologia Ciência e Profissão, 8, n 2, 3136.

Carvalho, A.M.A. (1984). Alguns elementos para uma reflexão sobre os rumos da profissão e da formaçāo. Psicologia Ciência e Profissão, 4, no 2, 7-9. Conselho Federal de Psicologia. (1994). Práticas emergentes e desafios para a formacão. São Paulo: Casa do Psicólogo.

Bastos, A.V.B.; Achcar, R. (1994). Dinâmica profissional e formação do psicólogo: uma perspectiva de integração. Em conselho Federal de Psicologia. Práticas emergentes e desafios para a formacão. ( $p$. 249-266). São Paulo: Casa do Psicólogo.

\section{Referências Bibliográficas}

